\title{
Research on the Path of China's Rural Green Development under the Governance System of "Three Integration Governance"
}

\author{
Hongxia Wei ${ }^{1, \text { a }}$ \\ ${ }^{1}$ School of Marxism, Anhui University of Finance and Economics, Bengbu, China \\ a1794686640@qq.com
}

\begin{abstract}
The governance system of "three integration governance" reflects the organic relationship of mutual supplement and restriction among autonomy, rule of law and rule of virtue. The governance system of "three integration governance" is not only the inevitable requirement of China's modern rural development, but also an important path to realize China's rural green development. The governance system of "three integration governance" provides multiple subject forces, legal system guarantee and spiritual and cultural power for the smooth implementation of China's rural green development. Discussing China's rural green development from the "three governance integration" rural governance system not only has important theoretical value, but also has a far-reaching practical impact on solving the practical problems faced by China's rural green development.
\end{abstract}

Keywords: Three integration governance, Governance system, Rural green development.

\section{Introduction}

The report of the 19th National Congress of the Communist Party of China takes "industrial prosperity, ecological livability, rural civilization, effective governance and rich life" as the general requirement of the Rural Revitalization Strategy. It can be seen that rural green development should become the meaning of rural response. Rural green development is an important part of China's green development strategy and the basis of China's green development. In recent years, with the proposal and implementation of five new development concepts (innovation, openness, coordination, green and sharing), China's rural green development has achieved remarkable results. However, there are still many practical problems, such as unreasonable industrial structure, insufficient protection of natural resources, serious natural environment pollution, insufficient green development infrastructure and so on. There are many reasons for these problems, among which the most critical is the imperfect rural governance system, which seriously affects the solution of the existing problems of rural green development. With the development of China's rural modernization, many practical problems have emerged in China's rural areas, such as the intensification of rural population outflow, the lack of agricultural productivity, the widening gap between urban and rural areas, and the obstruction of rural green development. In order to solve these practical problems, "three governance integration" governance system came into being. "The 'three governance' represents three different governance subjects of rural governance, which are equally important in the development of rural society. The 'integration of three governance' refers to the integration of the advantages of autonomy, rule of law and rule of virtue, which complement and restrict each other to promote the modernization of rural society."[1] Autonomy in the "integration of three governance" model is the core. Autonomy is to take the villagers as the main body and manage and solve various affairs in the village through the village "two committees" (village Party committee and village committee) in a democratic way. Villagers have dual roles in the process of autonomy. They are not only the administrator, but also the object of governance. Autonomy can not only mobilize the villagers' subjectivity and initiative, but also give full play to the role of grass-roots democratic system. However, autonomy has certain limitations. Due to the lack of effective supervision mechanism, it is easy to breed corruption, so it needs the cooperation of the rule of law. The rule of law is based on the formulation and implementation of the legal system. Through a strict legal system, it carries out strict and standardized management of rural affairs to prevent and punish the occurrence of illegal and criminal events. The rule of law is in the position of system guarantee in the "three governance integration" rural governance system, which is to solve the problem of rural illegal crime by means of coercion. If the rule of virtue is a hard constraint, then the rule of virtue is a soft constraint. Rule of virtue is to use the excellent rural traditional culture, folk culture, advanced socialist culture and socialist core values to guide the villagers in thought, cultural edification and moral education. Therefore, the villagers are urged to establish correct values and green development concept, consciously abide by village rules and regulations, laws and regulations, and actively participate in agricultural green production and rural ecological civilization construction." Autonomy is the basic requirement and realization form of socialist grass-roots democratic politics. The rule of law is the institutional guarantee that must be relied on in socialist modernization. The rule of virtue is the basic requirement that should be followed in inheriting Chinese traditional culture. Autonomy, the rule of law and the rule of virtue play their respective roles in rural social governance in the new era. Autonomy, the rule of law and the rule of virtue are both independent and closely related to each other, is an organic part of the rural governance system. In the rural governance system, the three are not simply juxtaposed. Autonomy is the goal pursued by the rule of law and the rule of virtue, the rule of law is an important guarantee for autonomy and the rule of virtue, and the rule of virtue is the traditional foundation support of autonomy and 
the rule of law. The ultimate goal of the "combination of three governance" rural governance system is to achieve effective rural governance and meet people's needs The people's sense of gain, security and happiness. "[2]The "three governance integration" rural governance system is not only conducive to maintaining the stability of rural order, promoting rural economic development and enhancing rural cultural prosperity, but also helps to promote rural green development and rural ecological civilization construction, and create a modern civilized village with good order, rich economy, honest folk customs and ecological beauty for villagers. Rural green development is one of the goals of leading rural governance. "Three governance integration" rural governance is the means and path to realize rural green development.

The role of the "three governance integration" governance system in promoting rural green development is mainly reflected in three aspects: First, it provides multiple subjects for rural green development and condenses the subject strength of rural green development. Second,it provides legal system guarantee for rural green development and escort rural green development. Third, it provides spiritual and cultural nourishment for rural green development and provides the source of spiritual power for rural green development. The degree to which the "three governance integration" governance system plays an important role in rural green development depends on the construction of the "three governance" governance system itself. Therefore, it is necessary for us to understand the current situation of the "three governance integration" governance system in the process of China's rural green development and find out deficiencies and countermeasures, so as to promote the further development of rural green development.

\section{Problems in the Governance System of "Three Governance Integration" in the Process of Rural Green Development}

\subsection{The Modernization of "Autonomy" in the Process of Rural Green Development in China Needs to Be Strengthened}

The report of the 19th National Congress of the Communist Party of China stressed that we should strengthen the basic work in rural areas, improve the rural governance system combining autonomy, rule of law and rule of virtue, and put forward new requirements for strengthening and improving the villagers' autonomy mechanism and the rural governance system of "integration of three governance", pointing out the direction for revitalizing the countryside and promoting the modernization of rural governance. "Over the years, rural governance based on villagers' autonomy has made remarkable achievements and should be affirmed. However, with the profound changes in rural society and the great changes in rural social structure, a series of new situations and problems have been spawned and triggered in rural areas, which poses a certain challenge to promote the modernization of rural governance."[3] The degree of modernization of villagers' autonomy depends on the maturity of democratic mechanism, which mainly depends on Villagers' enthusiastic participation in democratic decision-making, democratic supervision and democratic assessment of green development. From the current reality, there is a trend of "polarization" in the villagers' enthusiasm for participation in the current general election of villagers' committees and the decisionmaking of rural green development affairs. There are not only participation fanaticism based on their own interests, but also participation indifference caused by "inaction" and "disorderly action" of the village committee. The main reasons for this situation are as follows:

Firstly, it is affected by the traditional rural governance model. The traditional rural governance model is a top-down management and control model. Villagers are only the object of management and control, and there is no democracy. Although modern villagers' autonomy is based on democracy and the rule of law, grass-roots village committees, villagers, township enterprises and social organizations have the right to participate in the decision-making of green development affairs on an equal basis, and villagers are both administrators and governed, the old influence of the traditional rural management model is still difficult to eliminate, resulting in villagers Social organizations and township enterprises lack the subjectivity to participate in democratic decision-making.

Secondly, the villagers' awareness of green development is indifferent, the knowledge of green development is scarce, and they lack the consciousness to participate in the decisionmaking of green development affairs. Because the grass-roots township governments and village committees can not publicize the concept of green development and related knowledge to the villagers, the villagers do not understand green development at all, nor do they know that green development is related to their own vital and long-term interests, so the villagers lack the motivation to participate in democratic autonomy.

Thirdly, the villagers lack a sense of trust in the implementation of green development policies by grass-roots township governments. The supply of new public services such as rural environmental protection lags behind. Driven by the concept of GDP supremacy, some local governments ignore the environmental cost in the process of attracting investment, indiscriminately approve and develop, turn a blind eye to the transfer of high pollution and high emission enterprises to the countryside and serious rural garbage pollution, which directly affects the quality of life of rural residents. This attitude of local governments seriously frustrates the enthusiasm and enthusiasm of villagers to participate in democratic decision-making of green development [4].

\subsection{Modern "Rule by Virtue" Green Culture Needs to Be Cultivated in Rural Green Development}

First of all, the rural traditional view of nature is increasingly invaded by modern civilization. Traditional Chinese rural society is an acquaintance society with "differential order pattern" established based on human ethics. The maintenance of local social order mainly depends on internal education rather than external force. Villagers live a traditional farming life of working at sunrise and resting at sunset. In the cycle of four seasons, villagers are accompanied by cultivated land, forest land, lakes, grasslands, mountains and rivers, and people live in harmony with nature. The traditional festival of worshipping heaven and earth in local culture contains the green moral concept of respecting nature, worshipping nature and protecting nature. Under the influence of local culture, the villagers always uphold the moral concept of harmonious coexistence between man and nature. 
General secretary $\mathrm{Xi}$ Jinping said that cultural selfconfidence is a more basic, broader and deeper selfconfidence, and is a more basic, deeper and more lasting power. To a certain extent, the agricultural civilization bred, enriched and developed by the Chinese nation for 5000 years is the foundation and source of our firm cultural selfconfidence today. It requires us not to give up, abandon or dislike at any time. In fact, the simple materialism and primitive cosmic dialectics advocated by the ancients, such as "the unity of heaven and man", "Taoism and nature", "the unity of virtue with heaven and earth, the unity of brightness with the sun and moon, and the unity of order with the four seasons", all require us to cherish ecology, nature and land, so as to realize the harmonious coexistence and sustainable development between man and nature. However, with the development of China's social modernization, industrialization and urbanization, cities are expanding rapidly to rural areas, industrial parks, township enterprises and university towns are expanding, occupying a large number of farmland, and the area of cultivated land is shrinking sharply. Accordingly, the waste gas, waste water and solid pollutants discharged by industry also continue to damage the rural living environment. Local green moral values are increasingly eroded by urban modern civilization.

Secondly, rural green development "rule of virtue" brain drain. In the process of urbanization, a large number of rural elites gather in cities, resulting in a large loss of rural talents, poor circulation of rural governance elites, which hinders the demonstration role of folk elites. With the increasing hollowing out of villages and aging population, there is a serious lack of "rule of virtue" for rural green development. Therefore, how to inherit "rule of virtue" in Chinese villages at present Green traditional culture gene, cultivate modern green culture concept, and give full play to the leading role of "rule by virtue" green culture values, which is an important topic in front of rural green development.

\subsection{The Construction of "Rule of Law" in Rural Green Development Needs to Be Improved and Strengthened}

If "rule of virtue" plays a soft constraint role in rural green development, "rule of law" plays a hard constraint role. Rural green development needs perfect legal system and village rules and regulations to restrict and manage villagers' production and consumption. At present, there is no complete legal norm for rural green development, let alone a normalized "rule of law".

Firstly, the lack of laws and regulations for rural green development. At present, the construction of relevant laws, regulations and systems on rural green development is still in an imperfect state. China's laws and regulations related to green development mainly talk about environmental protection, resource conservation and recycling in a general sense, and focus on urban industrial development and enterprise production. There are very few laws and regulations for rural green development. Based on the needs of China's rural green development, how to promote the theme of agricultural green development, take green ecology as the guidance, innovate the system and mechanism of agricultural green development, carry out the construction of legal support system for agricultural green development, improve the legal and policy system, and provide guarantee for agricultural green development. Relevant laws and regulations need to be formulated for green development from the laws and regulations on the use of chemical fertilizers and pesticides, to the use mechanism of organic fertilizers for livestock and poultry, the management method of plastic film, the anti pollution reuse mechanism of straw, the land rotation and fallow system, and the green consumption, village appearance and infrastructure construction of rural farmers. In addition, the reward and punishment incentive system, assessment and supervision system of rural green development also need to formulate operable and implementable legal systems. Although the state has always attached great importance to the assessment and supervision of green development, and incorporated green development into the main content of the assessment of local governments. This is more obvious in industrial production and urban construction. However, there is no clear reward and punishment incentive system and assessment and supervision system for rural green development, especially the lack of specific assessment and supervision standards and quantification.

Secondly, judicial enforcement is weak. In the process of rural green development, vicious events such as waste of resources, deforestation, destruction of vegetation and wanton fishing occur frequently, but they have not been punished by law. Especially in key areas, such as fishing in the Yangtze River Basin, the growth and breeding period of aquatic organisms is seriously damaged, and overfishing occurs from time to time. The ecological vegetation on both banks of the Yellow River Basin has been damaged, and the phenomenon of soil erosion is serious. Such vicious events against green development escape from legal sanctions. The fundamental reason lies in the lack of laws and regulations related to rural green development and weak judicial enforcement.

\section{The Governance System of "Integration of Three Governance" is the Path Choice of China's Rural Green Development}

\subsection{Reform and Improve the Autonomy System of Rural Green Development and Pool Multiple Subject Forces}

Firstly, carry out scientific and effective management and cultivate villagers' consciousness of participating in green development. For example, through the point system management, the villagers can protect the ecological environment and advocate green production and lifestyle, so as to obtain perceptible points, and finally increase the weight for the year-end selection of "civilized family" and the distribution of relevant benefits, and even "one vote veto", so that the villagers can "fight without whipping", so that the villagers can internalize the awareness of ecological environmental protection and green development, Externalized in the line, spontaneously and voluntarily start with me and small things.

Secondly, improve the villagers' autonomy system and mobilize the villagers' enthusiasm to participate in the decision-making of green development affairs

In order to realize the benign development of political governance, the focus is to reposition the functions of various governance subjects. In terms of improving the governance system, we should improve the rural democratic election system and democratic decision-making system in 
accordance with the villagers' Committee Organization Law and the villagers' committee election law. In terms of standardizing democratic management, the villagers' autonomy charter and village rules and regulations are the democratic management system widely used in rural areas and an important support for farmers to participate in democratic management. Therefore, we should further improve the relevant provisions of the villagers' autonomy charter and village rules and regulations, ensure the democratic management of village affairs and mobilize the enthusiasm of villagers to participate in the decision-making of green development affairs.

Finally, formulate a scientific and reasonable assessment system to condense the strength of multiple subjects. Establish an environment-friendly index and carry out the evaluation and assessment of rural green development. The government, enterprises and the whole people should raise environmental awareness and develop an interactive and winwin relationship. Implement the target responsibility system for rural environmental governance, and implement the responsibility of energy conservation and environmental protection to the whole process and every link of rural construction; Guide villagers to actively participate in garbage classification and treatment activities, do not throw garbage at random, protect environmental sanitation, gather "micro behaviors" and form "public forces", so as to make the construction of rural green development have lasting vitality and move towards the road of rural green development.

A scientific and reasonable assessment, reward and punishment system will help to stimulate the enthusiasm and consciousness of village cadres in implementing the guidelines and policies of rural green development. The traditional assessment, reward and punishment system generally does not involve the content of green development, and only takes the level of GDP as the assessment standard. Therefore, in the process of rural development management, village cadres mainly focus on the improvement of GDP and invest less energy in sustainable utilization of ecological resources, environmental protection, green production and green consumption. Therefore, when rural cadres convey the green development policy to the villagers, or arrange the tasks of rural green development, the villagers often doubt the authenticity and credibility of their behavior. In order to improve the effectiveness of rural cadres' participation in rural green development and enhance the villagers' sense of trust in them, it is imperative to formulate an assessment, reward and punishment system including rural green development.

\subsection{Give Full Play to the Role of "Rule of Virtue" in Rural Green Development and Consolidate the Moral Foundation of Rural Green Culture}

With the acceleration of urbanization, "urban disease" is accompanied, and people are more and more eager to return to nature, "see mountains, see water, and remember homesickness". Therefore, rural governance must adhere to ecological priority and green development, revitalize rural civilization through creative transformation and innovative development of traditional agricultural civilization, and meet modern people's thirst and expectation for rural natural scenery with the reproduction of civilized rural style, good family style and simple folk style. Therefore, we must enhance the awareness of environmental protection, condense the ecological consensus of the masses, pay attention to cultivating the environmental protection awareness of the masses, and stimulate the endogenous driving force of their green development by guiding the masses to establish scientific ecological values and ethics.

Firstly, strengthen the exemplary and leading role of the Party branch. "Villages look at villages, households look at households, and farmers look at branches", strengthen grassroots party organizations, equip "leading geese" branch secretaries, and improve their environmental protection awareness and environmental governance ability through training and learning, so that they can set an example, play a good vanguard and exemplary role, influence and urge villagers to form a good habit of consciously caring for the environment, It can also cooperate with higher government departments to carry out special actions for environmental governance and strengthen supervision.

Secondly, we should pay special attention to the role of the education of local sages. It is necessary to widely stimulate the strength of villagers' sages such as veteran party members, veteran cadres and veteran teachers who live in the village. Under the organization and mobilization of the "two village committees", consciously instill the concept, culture and thought of ecological priority and green development into the villagers through popular and effective ways and forms such as folk art, literature and art, variety show and so on The profound truth contained in "protecting the ecological environment is protecting the productive forces, and improving the ecological environment is developing the productive forces" is willing to refer to and practice it in actual production and life.

Finally, cultivate rural environmental protection culture and form a social atmosphere in which everyone pays attention to environmental protection. Let farmers improve their environmental quality in direct learning and education. Rural areas can strengthen the publicity of environmental protection knowledge by setting up service centers for the people, places for cultural and sports activities, convenience education and publicity centers, etc; Publicize the concept and knowledge of environmental protection and sustainable development in popular language and close to life in the form of posters and environmental protection science popularization, carry out environmental protection experience introduction and villagers' exchange activities, and enhance the residents' concept of green development; Set up a new era farmers' seminar, and in the face of social hot issues concerned by the broad masses of farmers, give lectures on the policies related to the green development of rural areas of the CPC Central Committee, the State Council, provinces, cities and provinces. This includes ecological related industrial development, environmental policy, legal rights protection, practical technology, health knowledge and so on. Not only rural leading cadres take the lead in giving lectures, but also farming experts, agricultural technicians and rural teachers are important lecturers in the form of mass meetings, reports, seminars, etc. Through learning, mobilize farmers to closely combine the protection and governance of rural environment with their own interests and rural interests, so that farmers can improve their environmental quality in direct learning and education; Or by establishing village rules and regulations, public order and good customs, control old and bad habits. 


\subsection{Strengthen the Construction of "Rule of Law" for Rural Green Development and Provide Legal System Guarantee}

Firstly, improve the system of laws and regulations. At first, promote legislation in the field of agricultural green development. We will promote the formulation or revision of fishery law, Animal Husbandry Law, agricultural product quality and safety law, entry and exit animal and plant quarantine law, regulations on the protection of new plant varieties, regulations on the protection of basic farmland and other laws and regulations. Second, strengthen the legal guarantee of agricultural green development in key regions. We will improve the rules and regulations on the protection of the Yangtze River, study and draft the provisions on the protection and management of aquatic organisms in the Yangtze River, and promote the integration of ecological protection in the Yellow River basin into relevant laws and regulations. Third, carry out the construction of supporting regulations. Formulate or revise regulations on crop pest control, alien invasive species management, green consumption, resource recycling, rural environmental protection, etc. We will improve the responsibility pursuit system and damage compensation system for major environmental events and pollution accidents, and improve the punishment standards and illegal costs.

Secondly, strengthen law enforcement. First, strengthen law enforcement in key areas. Strictly implement laws and regulations in the fields of agricultural resources and environmental protection, quality and safety of agricultural products, production and use of agricultural input products, etc. We will intensify the investigation and handling of illegal cases such as damage to agricultural resources and the environment. Second, improve the law enforcement capacity of agricultural green development. We will promote comprehensive agricultural administrative law enforcement, strengthen the construction of law enforcement facilities and equipment, and promote the connection and cooperation of administrative law enforcement organs with judicial and supervisory organs.

In environmental protection law enforcement, we should gradually cover rural areas, so as to avoid the irreversible environmental pollution in rural areas and the transfer of urban and industrial pollution to rural areas. Strict implementation of environmental standards is conducive to a high starting point and high level of Rural Revitalization. At the same time, it should also be noted that more detailed and feasible policies and laws should be formulated according to the reality of rural economic development and the urban-rural differences between economic development and environmental protection, so as to ensure the green level of rural construction, take into account the law of rural economic development, and realize the sustainable and healthy development of rural construction. In addition, the possible environmental impact of agricultural production activities should be pre assessed, in-process supervision and post evaluation.

\section{Conclusion}

The rural governance system of "integration of three governance" uses the governance model of complementary and coordinated promotion of autonomy, rule of virtue and rule of law to condense multiple main forces, give play to the leading role of culture and provide a solid legal system guarantee for rural green development. Further along the principles and ideas of "three governance" in rural governance in the new era, promote the concept of "ecological priority and green development" to be deeply rooted in the hearts of the people, so that it can be continuously done in depth, detail and practice in the daily production and life of rural people. In terms of autonomy, we should better strengthen the construction of villagers' autonomy system, especially the construction of democratic system, so as to provide institutional guarantee for rural multiple subjects to participate in green legal affairs. In terms of the rule of law, we should comprehensively and systematically sort out, summarize the environmental protection laws and regulations related to rural revitalization, make them enter the village rules and regulations, and use them to standardize, restrict and supervise the daily words and deeds of the villagers, so as to truly act in accordance with the law, find a law in case of problems, solve problems and resolve contradictions, Make the thinking and mode of rule of law increasingly become the inner compliance and action of the villagers. In terms of rule of virtue, we should make full use of rural traditional local cultural resources, socialist core values and Marxist ecological cultural thought, give full play to the exemplary and leading role of local elites, adopt diversified publicity and education means, cultivate villagers' ethics of green development, and create a good social fashion of rural green development. In short, the "three governance integration" rural governance model helps to promote the cause of rural green development to a higher level.

\section{Acknowledgments}

This work is supported by the key research project of 2017 Anhui University Humanities and Social Sciences "Research on green development from the perspective of rural governance taking Huoqiu county, Anhui Province as an example" (Grant NO: SK2017A0450).

\section{References}

[1] Tang Jinwu. Research on the path of rural governance led by grass-roots party organizations -- Based on autonomy, rule of law and rule of virtue [J]. Journal of Yanbian Party School, 2021,No.4, P.49-54.

[2] Qiu Youdu. Rural governance system of "combination of three governance": connotation, significance and construction path [J]. Journal of Xichang University Social Science Edition, 2019 , No.1, P.25-29.

[3] $\mathrm{Qu}$ Bo.On the modernization of rural governance system [J]. Journal of Inner Mongolia Normal University (Philosophy and Social Science), 2018,No.1,P.15-18.

[4] Chen Yang. Research on rural governance in the process of modernization [J]. Journal of Yunnan Institute of socialism, 2018, No.4, P.137-141.

[5] Song Linlin, Zhao Minghua. Promoting rural green development and building an ecologically beautiful Shenyang taking the beautiful rural construction of Pijiabao village, Liuerbao Town, Liaozhong district as an example [J]. Journal of Liaoning Administrative College, 2018, No.5, P.72-74. 